\title{
Effect of pelleted cereal-based feed for addax antelope (Addax nasomaculatus) on feed intake and nutrient digestibility
}

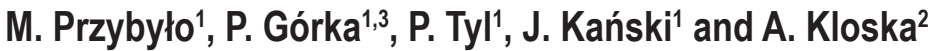 \\ ${ }^{1}$ University of Agriculture in Krakow, Faculty of Animal Sciences, Department of Animal Nutrition and Dietetics \\ al. Mickiewicza 24/28, 30-059 Kraków, Poland \\ ${ }^{2}$ Silesian Zoological Garden, Promenada gen. Jerzego Ziętka 7, 41-501 Chorzów, Poland
}

KEY WORDS: ruminants, antelope, captivity, concentrates, zoo

Received: $\quad 21$ March 2017

Revised: $\quad 7$ August 2017

Accepted: 2 November 2017

${ }^{3}$ Corresponding author:

e-mail: p.gorka@ur.krakow.pl

\begin{abstract}
The aim of this study was to determine the effect of pelleted cerealbased feed in the diet for addax antelope (Addax nasomaculatus) on feed intake and nutrient digestibility. Four addax females ( 3 years old) were allocated to 1 of 3 treatments according to $3 \times 3$ Latin square design and fed 3 diets. Each diet consisted of basal diet and meadow hay. In diet A basal diet consisted of a mixture of ground concentrates, chopped dehydrated lucerne, vegetables and fruits. In diet B $50 \%$ and in diet C $100 \%$ of dry matter (DM) provided with concentrates and chopped dehydrated lucerne in diet $A$ was replaced with a pelleted cereal-based feed. Meadow hay was offered ad libitum. Two females (sisters) were kept together through the study and thus pen was used as an experimental unit. The diets were formulated to be similar for crude protein and crude fibre content. DM intake (DMI) of basal diet did not differ between treatments $(P \geq 0.52)$ whereas DMl of hay and total DMl linearly decreased with increasing pellet inclusion in the basal diet $(P=0.05$ and $P=0.03$, respectively). Digestibility of neutral detergent fibre tended to linearly decrease $(P=0.09)$ and digestibility of hemicellulose linearly decreased $(P=0.05)$ with increasing pellet inclusion in the diet. Pelleted cereal-based feed used in the diet for addax had a negative effect on roughage intake and digestibility of structured carbohydrates compared to non-pelleted feed of similar nutrient composition.
\end{abstract}

\section{Introduction}

It is recommended that diets for wild captive ruminants should consist mostly of structured feeds (roughages, browse) with minimal addition of unstructured feeds (concentrates, fruits; Clauss and Dierenfeld, 2008). However, the widely used meadow or grass hay in the diets for captive ruminants, being often the only structured feed used for this group of animals in zoological gardens, is unwillingly consumed by many species, particularly by browsers and intermediate feeders (Taylor et al., 2013;
Górka et al., 2016). This leads to low structured feed intake and high proportion of unstructured feeds in the consumed diet (Schilcher et al., 2013; Taylor et al., 2013; Górka et al., 2016); however, energy-rich, unstructured feeds have an unfavourable influence on the fermentation pattern in the rumen (Gussek et al., 2016). Such a situation is considered as the main cause of diarrhoea, laminitis, poor body condition, short life span and post mortal signs of rumenitis, often reported in captive ruminants (Clauss and Dierenfeld, 2008; Taylor et al., 2013; Gattiker et al., 2014). The above mentioned problems can further 
increase when pelleted cereal-based feed is used in the diet. Pelleting and associated heat treatment of cereals increase fermentation rate of starch in the rumen (Bertipaglia et al., 2010). Furthermore, pelleted feed is eaten faster than not-pelleted feed (Waghorn and Reid, 1983; Górka et al., 2016). This together may result in ruminal digesta $\mathrm{pH}$ below the optimal for the functioning of the rumen, reduced fibre digestibility and, in consequence, lower feed intake (Plaizier et al., 2008; Castrillo et al., 2013).

Reluctant intake of structured feeds and a negative impact of high proportion of cereal-based feeds in the consumed diet on nutrient digestibility, health and longevity of captive ruminants is known predominantly for browsers and intermediate feeders (Clauss and Dierenfeld, 2008; Taylor et al., 2013; Górka et al., 2016). In this study we hypothesized that pelleted cereal-based feed would decrease nutrient digestibility and roughage intake by addax (Addax nasomaculatus) - a large Sahara desert grazer with long digesta retention time in the rumen (Hummel et al., 2008). The addax is a critically endangered species of antelope, as classified by the IUCN (IUCN SSC Antelope Specialist Group, 2016). Although extremely rare in its native habitat (the Termit Tin Toumma region of Niger), it is quite common in captivity. The aim of the study was to determine the effect of pelleted cereal-based feed in the diet for addax on feed intake and nutrient digestibility when compared to a non-pelleted cereal and lucerne-based diet of similar nutrient composition.

\section{Material and methods}

The study was conducted on four addax females (3 years old) in the Silesian Zoological Garden (Chorzów, Poland) between January and April 2014. Throughout the study two females (sisters, never separated) were kept together. As a result, pen was used as an experimental unit. It is worth mentioning that this study was conducted in parallel with the study of Górka et al. (2016), aiming to determine the effect of pelleted cereal-based feed used in the diet for sitatunga (Tragelaphus spekii). Therefore, experimental design used for these both studies was similar.

The experimental design was arranged as $3 \times 3$ Latin square design with 28-day periods: 7 days of gradual diet change, 14 days of diet adaptation and 7 days of data collection. Antelopes were fed 3 diets that resembled a typical diet used for addax in the Silesian Zoological Garden. Each diet was composed of basal diet and hay. In diet A basal diet consisted of a mixture of finely ground grains, oatmeal, soyabean meal, chopped dehydrated lucerne $(2-4 \mathrm{~cm})$, fresh vegetables and fruits and was fed at $2.25 \mathrm{~kg} \cdot \operatorname{animal}^{-1} \cdot \mathrm{d}^{-1}$. In diet B 50\% and in diet C $100 \%$ of dry matter (DM) provided with concentrates and chopped dehydrated lucerne in diet A was replaced with a commercial pelleted cerealbased feed (Complete Feed for Small Antelopes, Morawski, Kcynia, Poland), respectively. Meadow hay was offered ad libitum. Diets were formulated to be similar for crude protein (CP) and crude fibre content. So, soyabean meal and dehydrated lucerne inclusions in $\operatorname{diet} \mathrm{A}$ and $\mathrm{B}$ were balanced in order to achieve proper levels of these nutrients. The basal diet was offered in a stone trough and the hay in a hay rack. In order to avoid competition, two sets of feeders were used for the females that were kept together. The animals were fed once a day (10:00) and had ad libitum access to fresh water and mineral licks in addition to the meadow hay.

Feed intake was measured daily by weighing amount of feed offered and refused the next day. Representative samples of feeds $(0.5-1 \mathrm{~kg})$ were collected weekly, pooled by period of the study and kept dry (concentrates, hay) or frozen $\left(-18{ }^{\circ} \mathrm{C}\right.$; vegetables, fruits) for further analysis. Representative samples of faeces (not contaminated with urine) were collected from day 24 to 27 of each experimental period $\left(50 \mathrm{~g} \cdot \mathrm{d}^{-1}\right.$ from single females and $100 \mathrm{~g} \cdot \mathrm{d}^{-1}$ from the pen with two females), pooled by pen and experimental period and kept frozen $\left(-18^{\circ} \mathrm{C}\right)$ for analysis. Apparent total tract digestibility was calculated using acid insoluble ash (AIA) as digestibility marker. Dry matter output in faeces was calculated by dividing the AIA intake $\left(\mathrm{g} \cdot \mathrm{d}^{-1}\right)$ by AIA content in faeces $\left(\mathrm{g} \cdot \mathrm{kg}^{-1}\right.$ of DM), and subsequently DM intake and DM output was used to calculate apparent total tract digestibility. Feeds and faeces were analysed for DM, ash, CP, crude fat, crude fibre, neutral detergent fibre (NDF), acid detergent fibre, lignin and AIA as previously described by Górka et al. (2016). Cellulose content was calculated as ADF - lignin, and hemicellulose as NDF - ADF. Nonfibrous carbohydrate (NFC) content was estimated as $100-($ ash $+\mathrm{CP}+$ crude fat $+\mathrm{NDF})$.

Data were analysed as $3 \times 3$ Latin square design using the MIXED procedure of SAS (version 9.2 SAS Institute Inc., Cary, NC, USA). The statistical model included treatment and period as fixed effects, and pen as random effect. Polynomial contrasts were used to determine linear and quadratic effects of pelleted concentrate inclusion rate in the diet on feed intake and nutrient digestibility. Significance was declared at $P \leq 0.05$ and trends when $0.05<P \leq 0.10$. 


\section{Results}

Although basal diets were formulated to be similar for crude fibre, NDF content increased from $22.5 \%$ of $\mathrm{DM}$ for diet A to $25.1 \%$ of $\mathrm{DM}$ for diet $\mathrm{C}$ and hemicellulose increased from $9.6 \%$ of $\mathrm{DM}$ for $\operatorname{diet} \mathrm{A}$ to $12.2 \%$ of DM for diet C (Table 1). On the other hand, NFC content decreased from 56.9 to $52.7 \%$ of DM with increasing proportion of pelleted cereal-based feed in the diet.

There were only a few episodes of leftovers of the basal diet. Although refusals of hay were collected, some of the samples had clear signs of contamination with the urine. Therefore, refusals of hay were not analysed for chemical composition and, consequently, chemical composition of hay refusals was not taken into account in the calculation of nutrient intake and digestibility. Dry matter intake (DMI) of the basal diet was not different between treatments $(P \geq 0.52)$ whereas DMI of hay decreased linearly from 1.33 to $1.08 \mathrm{~kg} \cdot \mathrm{d}^{-1}$ $(P=0.05)$ with increasing inclusion of pelleted cereal-based feed in the diet (Table 2). As a result, total DMI decrease linearly from $2.53 \mathrm{~kg} \cdot \mathrm{d}^{-1}$ (diet A) to $2.25 \mathrm{~kg} \cdot \mathrm{d}^{-1}(\operatorname{diet} \mathrm{C} ; P=0.03)$. In line with the linear decrease of DMI, intake of $\mathrm{CP}$, crude fat, crude fibre, NDF, cellulose and NFC decreased or tended to decrease linearly $(P \leq 0.10)$ with increasing inclusion of pelleted feed in the diet, except for hemicellulose intake $(P=0.33)$, due to its slightly greater content in diets $\mathrm{B}$ and $\mathrm{C}$ in comparison to diet A. Total tract digestibility of crude fibre did not differ between treatments $(P \geq 0.16)$ but digestibility of NDF tended to decrease linearly $(P=0.09)$ and digestibility of hemicellulose decreased linearly $(P=0.05)$ with increasing proportion of pelleted cereal-based feed in the basal diet.

Table 1. Ingredients and chemical composition of diets

\begin{tabular}{|c|c|c|c|c|c|}
\hline \multirow{2}{*}{ Indices } & \multicolumn{3}{|l|}{ Diet $^{1}$} & \multirow{2}{*}{$\begin{array}{l}\text { Meadow } \\
\text { hay }^{2}\end{array}$} & \multirow{2}{*}{$\begin{array}{l}\text { Pelleted } \\
\text { feed }^{3}\end{array}$} \\
\hline & A & $\mathrm{B}$ & C & & \\
\hline $\mathrm{DM}, \%$ & $55.2 \pm 0.9$ & $55.1 \pm 0.7$ & $53.5 \pm 0.5$ & $91.1 \pm 0.1$ & $90.5 \pm 0.6$ \\
\hline \multicolumn{6}{|l|}{ Chemical components, \% DM } \\
\hline ash & $3.9 \pm 0.1$ & $5.2 \pm 0.1$ & $6.4 \pm 0.1$ & $7.1 \pm 0.8$ & $6.7 \pm 0.4$ \\
\hline crude protein & $13.7 \pm 0.4$ & $13.5 \pm 0.3$ & $13.5 \pm 0.4$ & $7.6 \pm 0.3$ & $14.6 \pm 0.6$ \\
\hline crude fat & $3.4 \pm 0.5$ & $2.8 \pm 0.4$ & $2.3 \pm 0.3$ & $1.1 \pm 0.2$ & $2.3 \pm 0.3$ \\
\hline crude fibre & $10.1 \pm 1.0$ & $10.1 \pm 0.9$ & $9.9 \pm 0.7$ & $34.0 \pm 2.2$ & $10.1 \pm 0.8$ \\
\hline $\mathrm{NDF}^{4}$ & $22.5 \pm 2.1$ & $24.4 \pm 1.3$ & $25.1 \pm 0.8$ & $65.9 \pm 3.5$ & $27.4 \pm 0.8$ \\
\hline hemicellulose & $9.6 \pm 1.4$ & $11.1 \pm 0.8$ & $12.2 \pm 0.8$ & $25.4 \pm 1.5$ & $13.6 \pm 0.8$ \\
\hline cellulose & $9.8 \pm 0.1$ & $10.1 \pm 0.1$ & $10.0 \pm 0.2$ & $35.2 \pm 3.3$ & $10.6 \pm 0.3$ \\
\hline $\mathrm{NFC}^{5}$ & $56.5 \pm 2.8$ & $54.1 \pm 2.0$ & $52.7 \pm 1.1$ & $18.3 \pm 3.7$ & $49.0 \pm 0.7$ \\
\hline $\mathrm{AlA}^{6}$ & $0.23 \pm 0.01$ & $0.32 \pm 0.01$ & $0.38 \pm 0.05$ & $2.7 \pm 0.72$ & $0.3 \pm 0.14$ \\
\hline \multicolumn{6}{|l|}{ Ingredients, $\mathrm{g} \cdot \mathrm{d}^{-1}$} \\
\hline pelleted feed & 0 & 627 & 1184 & & \\
\hline chopped dehydrated lucerne & 285 & 142 & 0 & & \\
\hline ground oat & 228 & 114 & 0 & & \\
\hline ground maize & 228 & 114 & 0 & & \\
\hline ground wheat & 228 & 114 & 0 & & \\
\hline oatmeal & 228 & 114 & 0 & & \\
\hline soyabean meal & 28 & 0 & 0 & & \\
\hline apple & 342 & 342 & 342 & & \\
\hline carrot & 342 & 342 & 342 & & \\
\hline beetroot & 342 & 342 & 342 & & \\
\hline Total, $\mathrm{g} \cdot \mathrm{d}^{-1}$ & 2251 & 2251 & 2210 & & \\
\hline
\end{tabular}

${ }^{1}$ diet: A - basal diet without pelleted feed inclusion; B - 50\% of concentrates and chopped dehydrated lucerne in the basal diet DM replaced with pelleted feed; $C-100 \%$ of concentrates and chopped dehydrated lucerne in the basal diet DM replaced with cereal-based pelleted feed; ${ }^{2}$ for each treatment meadow hay was offered ad libitum; ${ }^{3}$ complete feed for small antelopes (Morawski, Kcynia, Poland), consisting of (content in descending order according to the manufacturer declaration): ground cereals, meals with high protein content, cereal flour and bran, dried lucerne and grass, tree leaves, canary seed, molasses, vitamin-mineral supplement; ${ }^{4} \mathrm{NDF}$ - neutral detergent fibre; ${ }^{5} \mathrm{NFC}-$ non-fibrous carbohydrates = $100-\left(\right.$ ash + CP + crude fat + NDF); ${ }^{6} \mathrm{AIA}$ - acid insoluble ash 
Table 2. Effect of cereal-based pelleted feed inclusion in diet for addax on nutrient intake and nutrient digestibility (as measured using acid insoluble ash as internal marker)

\begin{tabular}{|c|c|c|c|c|c|c|}
\hline \multirow{2}{*}{ Indices } & \multicolumn{3}{|l|}{$\operatorname{Diet}^{1}$} & \multirow{2}{*}{ SEM $^{2}$} & \multicolumn{2}{|c|}{ Polynomial contrasts } \\
\hline & $\bar{A}$ & $B$ & $\mathrm{C}$ & & linear & quadratic \\
\hline \multicolumn{7}{|c|}{ Dry matter intake, $\mathrm{kg} \cdot \mathrm{d}^{-1}$} \\
\hline diet & 1.20 & 1.22 & 1.16 & 0.01 & 0.64 & 0.52 \\
\hline hay & 1.33 & 1.14 & 1.08 & 0.03 & 0.05 & 0.47 \\
\hline total & 2.53 & 2.36 & 2.25 & 0.03 & 0.03 & 0.76 \\
\hline \multicolumn{7}{|c|}{ Nutrient intake, $g \cdot d^{-1}$} \\
\hline organic matter & 2388 & 2214 & 2093 & 33 & 0.02 & 0.78 \\
\hline crude protein & 265 & 250 & 244 & 3 & 0.04 & 0.59 \\
\hline crude fat & 54 & 46 & 38 & 1 & $<0.01$ & 0.93 \\
\hline crude fibre & 575 & 513 & 484 & 13 & 0.04 & 0.61 \\
\hline $\mathrm{NDF}^{3}$ & 1144 & 1049 & 1015 & 22 & 0.10 & 0.63 \\
\hline hemicellulose & 451 & 423 & 420 & 8 & 0.33 & 0.62 \\
\hline cellulose & 585 & 527 & 502 & 12 & 0.05 & 0.62 \\
\hline $\mathrm{NFC}^{4}$ & 924 & 868 & 795 & 11 & 0.01 & 0.78 \\
\hline \multicolumn{7}{|c|}{ Apparent digestibility ${ }^{5}, \%$} \\
\hline organic matter & 60.6 & 56.4 & 53.6 & 3.6 & 0.17 & 0.90 \\
\hline crude protein & 60.7 & 56.9 & 54.8 & 2.9 & 0.12 & 0.77 \\
\hline crude fat & 67.5 & 54.7 & 42.9 & 8.6 & 0.24 & 0.98 \\
\hline crude fibre & 34.9 & 26.7 & 24.4 & 6.8 & 0.16 & 0.71 \\
\hline NDF & 40.3 & 31.8 & 28.3 & 5.9 & 0.09 & 0.58 \\
\hline hemicellulose & 59.3 & 51.1 & 44.7 & 5.9 & 0.05 & 0.99 \\
\hline cellulose & 40.0 & 31.8 & 31.9 & 5.7 & 0.12 & 0.43 \\
\hline NFC & 84.0 & 84.9 & 84.3 & 1.1 & 0.84 & 0.63 \\
\hline
\end{tabular}

${ }^{1}$ see Table $1 ;{ }^{2} \mathrm{SEM}$ - standard error of measurement; ${ }^{3} \mathrm{NDF}-$ neutral detergent fibre; ${ }^{4} \mathrm{NFC}-$ non-fibrous carbohydrates $=100-(\mathrm{ash}+\mathrm{CP}+$ crude fat + NDF); ${ }^{5}$ total tract digestibility

\section{Discussion}

Similar to our previous study (Górka et al., 2016), this experiment was stimulated by the fact that there are many different commercial feeds available on the market (with different ingredient and chemical compositions) and that there is still little known about how those feeds (not necessarily recommended for a particular species) affect feed intake, nutrient digestibility and also feeding behaviour of wild captive ruminants. As a result, in this study there are presented and compared different feeding practices used for the addax antelope in zoological gardens (the usage of ground or pelleted feed), at least in Poland, and thus a reasonable picture of weak points of those practices and their potential consequences for the health and welfare of addax antelope in captivity is provided.

Addax is classified as a typical grazer or grazer with minor amount of browse in the natural diet (Gagnon and Chew, 2000) and with anatomical and physiological characteristics considered typical for grazing ruminants (Hummel et al., 2008; Clauss et al., 2009; Tahas et al., 2017). This desert antelope living in Sahara is adapted to a low quality forage (high in fibre) and limited access to water by high particulate and fluid retention times in the rumen (Hummel et al., 2008). Although in the wild the addax forages predominantly on coarse and bulky roughages, in captivity often a high proportion of unstructured feeds can be found in the diet for this species (Schilcher et al., 2013), even though it is possible to maintain addax for a long time on a roughage-only diet (Tahas et al., 2017). In the current study, unstructured feed intake (mainly concentrates) ranged from 47 to $52 \%$ of the consumed DM. An even higher proportion of unstructured feed in the diet $(61 \%$ of DM) for addax was reported in other studies (Schilcher et al., 2013). Thus, current feeding practices of addax in the captivity do not follow widely propagated recommendations for zoo ruminants (Clauss and Dierenfeld, 2008; Schilcher et al., 2013; Gattiker et al., 2014).

In ruminants, microbes inhabiting the rumen play a key role in nutrient digestion, particularly digestion of structured carbohydrate (fibre), the main source of energy for these species. Fibre digestibility in the rumen is negatively affected by high concentrate intake and the associated reduction in the ruminal pH (Jaakkola and Huhtanen, 1993; 
Plaizier et al., 2008), due to, inter alia, negative impact of low ruminal $\mathrm{pH}$ on rumen microbes involved in fibre digestion (Plaizier et al., 2008). This results in longer fibre retention time in the rumen (Jaakkola and Huhtanen, 1993) and may depress feed intake (Plaizier et al., 2008). Even more pronounced decrease in fibre digestion can be expected when a high concentrate intake is combined with pelleted cereals. Pelleting affects starch gelatinization and its extent and rate of fermentation in the rumen, resulting in higher postprandial short chain fatty acids concentration in the rumen and lower ruminal pH (Castrillo et al., 2013; Gimeno et al., 2015). Furthermore, pelleted feed is eaten faster than ground or not ground feed (Waghorn and Reid, 1983; Górka et al., 2016), which may further lower ruminal $\mathrm{pH}$, at least shortly after feeding. Unstructured feed intake was generally very high for all treatments $(\geq 47 \%$ of consumed DM). In a situation when the rumen is expected to be challenged with a low or very low $\mathrm{pH}$, due to a high unstructured feed intake, each additional factor increasing the probability of ruminal $\mathrm{pH}$ drop below optimal for rumen functioning (e.g., feed pelleting) may lead to substantial changes in nutrient digestion and feed intake. Also, as inclusion of pelleted cereal-based feed in the diet increased, the proportion of chopped dehydrated lucerne decreased or was lacking in the $\operatorname{diet}(\operatorname{diet} \mathrm{C})$. The particle size of chopped dehydrated lucerne used in the current study $(2-4 \mathrm{~cm})$ allows for classifying it as a structured feed. In consequence, the time spent for ruminating could be shorter when pelleted compound feed replace ground concentrates and chopped dehydrated lucerne in the diet, leading to higher probability of ruminal acidosis (Plaizier et al., 2008). Furthermore, lower hay intake of diet $\mathrm{B}$ and $\mathrm{C}$ could further translate into less time spent for rumination, lower saliva secretion and an associated lower buffering capacity of the rumen; however, rumination time and saliva secretion were not controlled in the current study. Taken together, a combination of high unstructured feed intake and presence of pelleted concentrates in the diet could explain the decrease of both hay intake and fibre digestibility when proportion of pelleted cereal-based feed in the diet increased. In support of this hypothesis, Schilcher et al. (2013) showed severe lesions of rumen mucosa in addax antelope when unstructured feeds accounted for $61 \%$ of dietary DM. As a result, low or very low ruminal $\mathrm{pH}$ in addax may not be a marginal problem in captivity, or addax is very vulnerable to bouts of ruminal acidosis. Thus, rations with pelleted concentrates, potentially characterized with high fermentation rate in the rumen, should be avoided, as these may depresses forage intake and negatively affect gastrointestinal tract functionality of the addax, a critically endangered ruminant species (IUCN SSC Antelope Specialist Group, 2016).

Pelleting is known to decrease digesta retention time in the rumen, leading to less time available for the microbial digestion of fibre (Abouheif et al., 2012). Such a situation could also partially explain lower fibre digestion when pelleted cerealbased feed was used in the diet. In the current study from 20 to $23 \%$ of cellulose and from 25 up to $34 \%$ of hemicellulose was consumed with unstructured feeds. Greater hemicellulose intake with unstructured feeds for diet B and C, in comparison to diet A, was a result of a slightly greater hemicellulose content in the basal diet when pelleted feed replaced ground concentrates and chopped dehydrated lucerne and lower hay intake for those treatments. Retention time in the rumen may be especially important for efficiency of fibre digestion in the addax, a species naturally having a very long digesta retention time in the rumen (Hummel et al., 2008). However, shorter rumen retention time when pelleted feeds were used in the diet does not explain the lower hay intake of diet B and C. More work is needed to determine the effect of different physical structure of the diet, and its ingredient and chemical composition on digesta retention time and digestibility of nutrient in addax.

As already mentioned, inclusion of pelleted cereal-based feed resulted in lower inclusion or lack of chopped dehydrated lucerne in the diet. Furthermore, the ingredient composition of pelleted cereal-based feed was different from the ingredient composition of concentrates routinely fed to addax in the Silesia Zoological Garden. Therefore, results of this study do not give an unequivocal answer whether observed differences between treatments were solely a result of physical form of concentrates (e.g., pellet) and this should be taken into account when interpreting the data. However, a large variety of commercial pelleted feeds for zoo ruminants is available on the market. The current study and our parallel study (Górka et al., 2016) increase our knowledge on potential advantages and disadvantages for using cereal-based diets in zoo ruminants.

\section{Conclusions}

Under the conditions of the current study the pelleted cereal-based feed used in the diet for addax had a negative effect on roughage (meadow hay) intake and digestibility of structured carbohydrates in comparison to non-pelleted feed of similar nutrient composition. 


\section{References}

Abouheif M.A., Al-Saiady M.Y., Al-Mufarrej S.I., Makkawi A., Ibrahim H.A., Aljumaah R.S., 2012. Effect of physical form of diet and frequency of feeding on digesta retention time and digestion in Najdi lambs. J. Anim. Vet. Adv. 11, 1774-1779, https://doi.org/10.3923/javaa.2012.1774.1779

Bertipaglia L.M.A., Fondevila M., van Laar H., Castrillo C., 2010. Effect of pelleting and pellet size of a concentrate for intensively reared beef cattle on in vitro fermentation by two different approaches. Anim. Feed Sci. Technol. 159, 88-95, https://doi. org/10.1016/j.anifeedsci.2010.05.010

Castrillo C., Mota M., Van Laar H., Martín-Tereso J., Gimeno A., Fondevila M., Guada J.A., 2013. Effect of compound feed pelleting and die diameter on rumen fermentation in beef cattle fed high concentrate diets. Anim. Feed Sci. Technol. 180, 34-43, https://doi.org/10.1016/j.anifeedsci.2013.01.004

Clauss M., Dierenfeld E.S., 2008. The nutrition of "browsers". In: M.E. Fowler, R.E. Miller (Editors). Zoo and Wild Animal Medicine. Current Therapy. $6^{\text {th }}$ Edition. Saunders Elsevier. St. Louis, MO (USA), pp. 444-454, https://doi.org/10.1016/B978141604047-7.50058-0

Clauss M., Fritz J., Bayer D., Nygren K., Hammer S., Hatt J.-M., Südekum K.-H., Hummel J., 2009. Physical characteristics of rumen contents in four large ruminants of different feeding type, the addax (Addax nasomaculatus), bison (Bison bison), red deer (Cervus elaphus) and moose (Alces alces). Comp. Biochem. Physiol. A - Mol. Integr. Physiol. 152, 398-406, https://doi.org/10.1016/j.cbpa.2008.11.009

Gagnon M., Chew A.E., 2000. Dietary preferences in extant African Bovidae. J. Mammal. 81, 490-511, https://doi. org/10.1644/1545-1542(2000)081<0490:DPIEAB>2.0.CO;2

Gattiker C., Espie I., Kotze A., Lane E.P., Codron D., Clauss M., 2014. Diet and diet-related disorders in captive ruminants at the national zoological gardens of South Africa. Zoo Biol. 33, 426-432, https://doi.org/10.1002/zoo.21150

Gimeno A., Al Alami A., Toral P.G., Frutos P., Abecia L., Fondevila M., Castrillo C., 2015. Effect of grinding or pelleting high grain maize- or barley-based concentrates on rumen environment and microbiota of beef cattle. Anim. Feed Sci. Technol. 203, 67-78, https://doi.org/10.1016/j.anifeedsci.2015.03.003

Górka P., Przybyło M., Kański J., Kloska A., 2016. Effect of pelleted cereal-based feed used in the diet on feed intake, eating behaviour, rumination and nutrient digestibility in antelope sitatunga (Tragelaphus spekii). J. Anim. Feed Sci. 25, 125-133, https://doi.org/10.22358/jafs/65572/2016
Gussek I., Große-Brinkhaus C., Hummel J., Südekum K.-H., 2016. Chemical composition and fermentation characteristics of feedstuffs for giraffes (Giraffa camelopardalis) in German zoos. J. Anim. Feed Sci. 25, 134-144, https://doi.org/10.22358/ jafs/65573/2016

Hummel J., Steuer P., Südekum K.-H., Hammer S., Hammer C., Streich W.J., Clauss M., 2008. Fluid and particle retention in the digestive tract of the addax antelope (Addax nasomaculatus) - adaptations of a grazing desert ruminant. Comp. Biochem. Physiol. A - Mol. Integr. Physiol. 149, 142-149, https://doi.org/10.1016/j.cbpa.2007.11.001

IUCN SSC Antelope Specialist Group, 2016. Addax nasomaculatus. The IUCN Red List of Threatened Species 2016: e.T512A50180603, https://doi.org/10.2305/IUCN.UK.2016-2. RLTS.T512A50180603.en

Jaakkola S., Huhtanen P., 1993. The effects of forage preservation method and proportion of concentrate on nitrogen digestion and rumen fermentation in cattle. Grass Forage Sci. 48, 146-154, https://doi.org/10.1111/j.1365-2494.1993.tb01847.x

Plaizier J.C., Krause D.O., Gozho G.N., McBride B.W., 2008. Subacute ruminal acidosis in dairy cows: The physiological causes, incidence and consequences. Vet. J. 176, 21-31, https://doi. org/10.1016/j.tvjl.2007.12.016

Schilcher B., Baumgartner K., Geyer H., Liesegang A., 2013. Investigations on rumen health of different wild ruminants in relation to feeding management. J. Zoo Aquar. Res. 1, 28-30, https://doi.org/10.19227/jzar.v1i1.14

Tahas S.A., Martin Jurado O., Hammer S., Arif A., Reese S., Hatt J.-M., Clauss M., 2017. Gross measurements of the digestive tract and visceral organs of addax antelope (Addax nasomaculatus) following a concentrate or forage feeding regime. Anat. Histol. Embryol. 46, 282-293, https://doi.org/10.1111/ahe.12268

Taylor L.A., Schwitzer C., Owen-Smith N., Kreuzer M., Claus M., 2013. Feeding practices for captive greater kudus (Tragelaphus strepsiceros) in UK collections as comparted to diets of freeranging specimens. J. Zoo Aquar. Res. 1, 7-13, https://doi. org/10.19227/jzar.v1i1.18

Waghorn G.C., Reid C.S.W., 1983. Rumen motility in sheep and cattle given different diets. N. Z. J. Agric. Res. 26, 289-295, https:// doi.org/10.1080/00288233.1983.10427032 